Original Research

\title{
Citrus limon L. (lemon) seed extract shows neuro-modulatory activity in an in vivo thiopental-sodium sleep model by reducing the sleep onset and enhancing the sleep duration
}

Md. Mominur Rahman ${ }^{1}$, Fahadul Islam ${ }^{1}$, Anwar Parvez ${ }^{1}$, Md. A.K. Azad ${ }^{1}$, Ghulam Md Ashraf ${ }^{2,3}$, Mohammad Fahad Ullah ${ }^{4, *}$ Muniruddin Ahmed ${ }^{1, *}$

${ }^{1}$ Department of Pharmacy, Faculty of Allied Health Sciences, Daffodil International University, 1207 Dhaka, Bangladesh

${ }^{2}$ Pre-Clinical Research Unit, King Fahd Medical Research Center, King Abdulaziz University, 21589 Jeddah, Saudi Arabia

${ }^{3}$ Department of Medical Laboratory Technology, Faculty of Applied Medical Sciences, King Abdulaziz University, 21589 Jeddah, Saudi Arabia

${ }^{4}$ Prince Fahd Research Chair, Department of Medical Laboratory Technology, Faculty of Applied Medical Sciences, University of Tabuk, 47311 Tabuk, Saudi Arabia

*Correspondence: drmuniruddin@gmail.com (Muniruddin Ahmed); m.ullah@ut.edu.sa (Mohammad Fahad Ullah)

DOI:10.31083/j.jin2101042

This is an open access article under the CC BY 4.0 license (https://creativecommons.org/licenses/by/4.0/).

Submitted: 24 May 2021 Revised: 28 July 2021 Accepted: 14 September 2021 Published: 28 January 2022

Citrus limon L. is an ingenious alternative medication and has a broad scope in managing several health conditions as part of natural remedies. Recently, medicinal plants have witnessed incredible consideration worldwide in the field of neuroscience for remedial intervention. The present work has investigated the phytochemical compounds and neuropharmacological potential of the seed extract of Citrus limon as a step to partially validate its formulations as nutraceuticals using an in vivo model. Diverse phytochemical groups such as alkaloids, glycosides, flavonoids, tannins, gums, saponins, steroids were qualitatively identified through colorimetric methods utilizing standard compounds. The neuropharmacological properties were studied in Swiss albino mice with the sleep time induced by thiopental sodium taken as an end-point, in standard hole cross, hole board, and open-field experiments at varying doses of 50 and 100 $\mathrm{mg} / \mathrm{kg}$ body weight. Phytochemical screening showed that alkaloids, flavonoids, saponins, tannins, steroids, and glycosides are present in the aqueous extract of the seed. The extracts demonstrated a significant reduction in sleep onset and enhanced the sleep duration in a dose-dependent manner in thiopental sodium-induced sleeping time, along with a marked decrease in unconstrained locomotors and explorative properties in both hole cross and open field tests. Moreover, in the hole board study, the extracts minimized the count of head dips observed in the treated mice. The results shown in this study demonstrate that Citrus limon extracts have neuropharmacological properties that can be further examined for their potential role as an adjuvant with conventional medications or nutraceuticals.

\section{Keywords}

Neurological disorders; Phytochemical compounds; Latent period; Neuropharmacological potential; Nutraceuticals

\section{Introduction}

Recently, a stressed lifestyle has been linked to an assortment of psychiatric disorders, and evidence suggests that depression is an unavoidable medical concern in these disorders
[1-4]. Different antipsychotic drugs, namely, tricyclic antidepressants, monoamine oxidase inhibitors, and serotonin re-uptake inhibitors, are available to manage various psychotic problems, but several side effects are gradually hindering their use in a long-term therapeutic regimen $[5,6]$. Thus, the quest for new anxiolytic substances with minimal unfavorable impact is still an area of interest being explored for an appropriate pharmacological effect. Certain organic substances, particularly restorative herbs, are commonly known to be the primary armamentarium of concoction compounds with enormous remedial potential. Neuropsychiatric disorders such as depression are common, corresponding to a state of mental illness that may result in severe symptoms such as sadness, feelings of guilt and loss of interest which affect sleeping, dietary intake, cognitive and psychomotor guided daily activities. Depression and anxiety, if they remain untreated, may aggravate the symptoms, worsen the complications, and ultimately lead to suicidal ideation risks $[7,8]$. The actual etiology of depression and anxiety is still unknown. However, these may arise due to continued disruption of the antioxidant defense system and an enhanced redox imbalance or oxidative stress [9]. The redox stress in the brain supports cellular conditions that cause neurological damage and related cognitive deteriorations [10-13].

Citrus limon belongs to the Rutaceae family, with a predominant presence in South Asia, including Northeastern India. Citrus limon is the most notable citrus species, with an affluent mercantile value. Most types of citrus plants are substantial evergreen bushes or small trees, 5-15 meters tall. The tree's ellipsoidal yellow fruit is used worldwide for culinary and non-culinary purposes and is an active ingredient of folk medicine and functional foods. The lemon juice is around 5 to 6 percent citrus extract, having an acrid flavor with a 
$\mathrm{pH}$ of about 2.2. The distinctively harsh flavor of lemon juice makes it an essential constituent of drinks and nutritional supplements, including lemonade and lemon meringue pie. Its berry is essentially rich in alkaloids which show anticancer properties and demonstrates antibacterial activities in unrefined concentrations of lemon on clinically challenging bacterial strains [14-21]. The biological activity of $C$. limon is attributed to the rich quantity of phenolic compounds, for instance, flavonoids; limonoids, carotenoids and bioactive monoterpenoids such as D-limonene, $\beta$-pinene and $\gamma$ terpinene [22]. These chemical compounds are the factor for the significant utilization of $C$. limon in the food and cosmetics industries [23-28]. The scientifically proven therapeutic activities of $C$. limon include anti-inflammatory, antimicrobial, antioxidant, anticancer, and antiparasitic actions. Citrus flavonoids may also modulate blood platelet functions and have an anti-aggregatory effect $[29,30]$. To further explore the pharmacological properties of $C$. limon, the current investigation focused on the neuro-pharmacological benefits of this plant in the in vivo mouse model.

\section{Materials and methods}

\subsection{Chemicals and drugs}

Thiopental Sodium and diazepam were purchased from Incepta Pharmaceuticals Ltd (Dhaka, Bangladesh and Opsonin Pharma Ltd (Dhaka, Bangladesh). Distilled water and different reagents were obtained from BDH Chemicals Ltd (Dhaka, Bangladesh).

\subsection{Plant materials}

The seeds were obtained from 45-50 completely ripened fruits of the 4-5 Citrus limon plants, which were mature and aged 2-2.5 years, grown in fields close to Jahangirnagar University in Dhaka, Bangladesh, on 23rd October 2020. These were authenticated from Bangladesh National Herbarium, Mirpur, Dhaka.

\subsection{Preparation of plant extract}

The seeds collected from Citrus limon were carefully washed with distilled water to remove undesired natural parts. The seeds of the plants were dried under sunlight (temperature approximately $30-35^{\circ} \mathrm{C}$ ) for two days and stored for seven days in an air-tight container. The dried seeds were ground to a coarse powder. The prepared fine powder was packed in a container and stored in cool, dark, and dry conditions to prepare fresh extracts before the investigation. A quantity of $500 \mathrm{gm}$ of seed powder of Citrus limon was dissolved in $1000 \mathrm{~mL}$ of water in a glass compartment for 2-3 days, with standard shaking and mixing. Afterward, the entire mixture was passed through a fine, white cotton cloth. Further filtration was done using Whatman filter paper. Extracts were obtained by the evaporation of solvent that was kept in open space. The yield value of the extracts from the lemon seeds was $2.65 \% \mathrm{w} / \mathrm{w}$ [31].

\subsection{Experimental animals}

Ninety Swiss albino mice (22-25 g) aged 6-7 weeks were obtained from Jahangirnagar University, Dhaka, Bangladesh. The animals were caged under standard natural conditions (22-25 ${ }^{\circ} \mathrm{C}$, humidity 60-70\%, 12-hour light: 12-hour dull cycle). These were given a standard pellet diet, which was obtained from Jahangirnagar University, Dhaka. All protocols considered in our study, including animals, were approved by the Faculty of Allied Health Sciences Research Ethics Committee, Daffodil International University, Dhaka1207, Bangladesh. (Ref: FAHSREC/DIU/2020/1006).

\subsection{Qualitative phytochemical screening}

Qualitative assessment was done using colorimetric procedures with standard substances, indicating specific phytochemical groups, for example, glycosides, flavonoids, tannins, alkaloids, gums, steroids, saponins [32]. For carbohydrates, Molisch and Fehling's tests were used. Identification of flavonoids was based on the standard flavonoid test. The Dragendroff's, Mayer's, and Hager's tests were used for alkaloids. Potassium dichromate test, ferric chloride, and lead acetic acid derivation tests were pursued for tannins. For glycosides, Keller-Kiliani tests were performed. A frothing test was done for the presence of saponins. To detect steroids, the sulphuric acid analysis was performed. For detecting the presence of gum in the extracts, the Molisch test was further used.

2.6 Quantitative determination of some phytochemical constituents

Harborne's (1973) method was used to analyze alkaloids: $5 \mathrm{~g}$ of the sample was weighed into a $250 \mathrm{~mL}$ beaker, and 200 $\mathrm{mL}$ of $10 \%$ acetic acid in ethanol was added, capped, and set aside for 4 hours. This was filtered, and the extract was concentrated to one-quarter of its original volume using a water bath. Dropwise additions of concentrated ammonium hydroxide to the extract were made until the precipitation was accomplished. The entire solution was allowed to settle and rinsed with weak ammonium hydroxide before being filtered. The residual alkaloid content was desiccated and weighed. Van-Burden and Robinson's (1981) method was used to determine tannin: A $50 \mathrm{~mL}$ plastic bottle filled with $500 \mathrm{mg}$ of the sample. In a mechanical shaker, $50 \mathrm{~mL}$ of distilled water was added and agitated for 1 hour. This was then filtered into a $50 \mathrm{~mL}$ volumetric flask and brought up to the required concentration. The filtrate was then pipetted into a test tube with $2 \mathrm{~mL}$ of $0.1 \mathrm{M} \mathrm{FeCl}_{3}$ in $0.1 \mathrm{~N} \mathrm{HCl}$ and $0.008 \mathrm{M}$ potassium ferrocyanide. Within 10 minutes, the absorbance was taken at $120 \mathrm{~nm}$. Bohm and Kocipai Abyazan's (1994) procedure was used for flavonoid determination: At room temperature, 10 $\mathrm{g}$ of the plant sample was extracted many times with $100 \mathrm{~mL}$ of $80 \%$ aqueous methanol. Whatman filter paper No 42 was used to filter the entire solution $(125 \mathrm{~mm})$. The filtrate was then placed in a beaker and dried over a water bath before being weighed at a consistent weight [33-35]. 


\subsection{Sleeping time induced by thiopental sodium}

The technique defined by Raihan MO et al. [36] was used to study the impact of the lemon seed extracts on sleeping time experiments induced by thiopental sodium. For such an objective, mice were grouped into six groups, with five $(n=$ 5) mice in each group. Group I was used as a control and given distilled water (10 mL/kg b.w.), group II, as usual, diazepam ( $0.50 \mathrm{mg} / \mathrm{kg}$ b.w.) was used as standard and groups III, IV, V and VI were used for the seed extracts. Group II, III, IV, V and VI were administered orally using cannula, the standard drug diazepam $(0.50 \mathrm{mg} / \mathrm{kg}$ b.w. and seed extracts in the doses: 25, 50, 100 and $200 \mathrm{mg} / \mathrm{kg}$ b.w. After thirty minutes, thiopental sodium ( $20 \mathrm{mg} / \mathrm{kg} \mathrm{b.w.)} \mathrm{was} \mathrm{injected} \mathrm{in-}$ traperitoneally to all assortments to induce sleep. For monitoring adverse effects (if any), single mice from each group were placed on the table and examined. The length of sleep induced by thiopental sodium in animals was determined as indicated by the loss of their correct reflex. The percentages of effects were calculated using the following equation:

$$
\text { Effect }(\%)=\frac{\text { The average duration of loss of righting reflex in the test group }}{\text { The average duration of loss of righting reflex in the control group }} \times 100
$$

\subsection{Hole cross test}

This investigation was carried out as described in the past by Uddin et al. [37]. A cage was utilized that has a size of $35 \times 25 \times 20 \mathrm{~cm}$. In the enclosure, a segment was marked. At the height of $7.5 \mathrm{~cm}$ at the enclosure's central focus, a hole with a diameter of $3 \mathrm{~cm}$ was created. Mice were administered with control, standard, or extract treatment and were put on one side of the platform. The number of passages taken by the mouse in each group through the hole from one chamber to another was then counted for $3 \mathrm{~min}$ at intervals 0,30 , 60,90 , and $120 \mathrm{~min}$ after administering the control, standard, and test sample (p.o.). This experiment was conducted within two days. Group I was set as control and given distilled water $(10 \mathrm{ml} / \mathrm{kg}$ b.w.), and group II had taken diazepam $(1 \mathrm{mg} / \mathrm{kg}$, b.w.), which was used as standard. Groups III and IV were given seed extracts of 50 and $100 \mathrm{mg} / \mathrm{kg}$ body weight, respectively.

$\operatorname{Inhibition~}(\%)=\frac{\text { Mean No. of movements (control) }- \text { Mean No. of movements (test) }}{\text { Mean No. of movements (control) }} \times 100$

\subsection{Hole board test}

The test was performed as described by Kamei J et al. [38] with slight deviations. For the present test, a level platform of $90 \mathrm{~cm} \times 90 \mathrm{~cm}$ in radius with 16 equitably separated holes was utilized. This stage likewise had a frame of $5 \mathrm{~cm}$ in height. Mice were grouped into four groups; control, standard, and test. Five $(n=5)$ mice were in each group. Group 1 (10 $\mathrm{mL} / \mathrm{kg} \mathrm{b.w.)} \mathrm{was} \mathrm{listed} \mathrm{for} \mathrm{control} \mathrm{and} \mathrm{took} \mathrm{distilled} \mathrm{water.}$ As standard, diazepam was provided to group II $(1 \mathrm{mg} / \mathrm{kg}$, b.w., p.o.). Groups III and IV independently took seed extracts in 50 and $100 \mathrm{mg} / \mathrm{kg}$ b.w. doses. The number of head dips in single mice into the holes was monitored for $10 \mathrm{~min}$ after the application.

Inhibition $(\%)=\frac{\text { Mean No. of head dips (control) - Mean No. of head dips (test) }}{\text { Mean No. of head dips (control) }} \times 100$

\subsection{Open field test}

The method described by Gould TD et al. [39] was used for this analysis. The test device is made up of a plane $0.5 \mathrm{~m}^{2}$ field with a square progression. The squares on the other side are painted black and white. The experimental board is identical to a chessboard. Likewise, the mechanical system had a compartment height of $0.1 \mathrm{~m}$. Mice were aligned into four groups. There were five $(n=5)$ mice in every group. Group I was assessed as control and given distilled water $(10 \mathrm{~mL} / \mathrm{kg}$ b.w.). Diazepam (1 mg/kg, b.w., p.o.), which was deemed standard, was given to Group II. Seed extract doses of 50 and $100 \mathrm{mg} / \mathrm{kg}$ b.w. were distinctly provided to Groups III and IV. The number of squares moved at any pace by the animals in each treated group was measured for $3 \mathrm{~min}$ at the time intervals $0,30,60,90$, and $120 \mathrm{~min}$ after the oral administration of test medication,

$\operatorname{Inhibition~}(\%)=\frac{\text { Mean No. of movements }(\text { control })-\text { Mean No. of movements }(\text { test })}{\text { Mean No. of movements }(\text { control })} \times 100$

\subsection{Statistical analysis}

Results are shown as mean \pm SEM. Analyzes were carried out using one-way ANOVAs followed by Dunnett's post hoc tests for sleeping time and hole board data. Two-way ANOVAs followed by Bonferroni's post hoc tests were used for hole cross and open-field data. As a statistical result, $p<$ 0.05 was reported as significant.

\section{Results \\ 3.1 Aqueous seed extract shows a variety of bioactive phytochemicals}

A comprehensive range of chemical tests for identifying major classes of therapeutically significant compounds exhibited alkaloids, flavonoids, tannins, steroids, and cardiac glycosides in the aqueous extract of the Citrus limon seed. In contrast, saponins were found to be absent. Phytochemical compounds of Citrus limon aqueous extract of seeds are shown in Table 1. Quantitative estimation for certain phytoconstituents such as alkaloids, flavonoids and tannins in Citrus limon seed extract is also summarized in Table 2. The estimations found tannins to be present in good proportion compared to other molecules.

\subsection{Lemon seed extract induces neuromuscular sedation in the thiopental $\mathrm{Na}$ - sleep model}

In the thiopental-induced hypnosis test, the plant extracts have shown a significant reduction in sleep onset and enhanced sleep duration in a dose-dependent manner. In this study, seed extract at doses of $25,50,100$, and $200 \mathrm{mg} / \mathrm{kg}$ demonstrated a substantial decrease in sleep onset and increased sleeping time dependent on the dose (Table $3 / p<$ 0.05). The length of thiopental sodium-induced sleep time 
Table 1. Phytochemical compounds of Citrus limon (lemon) seed extracts.

\begin{tabular}{lc}
\hline Compounds & Seed (aqueous extracts) \\
\hline Alkaloids & ++ \\
Flavonoids & + \\
Saponins & - \\
Tannins & + \\
Steroids & ++ \\
Gums & + \\
Cardiac glycosides & + \\
\hline
\end{tabular}

All tests were carried out in triplicates.

KEY: ++, Highly detected; +, Less detected; -, Not detected.

Table 2. Percentage of alkaloids, tannin and flavonoids in the citrus limon seed extract.

\begin{tabular}{lc}
\hline Phytochemical class & Quantity (\%) \\
\hline Alkaloids & $0.36 \pm 0.2$ \\
Flavonoids & $0.34 \pm 0.10$ \\
Tannins & $12.14 \pm 0.12$ \\
\hline \multicolumn{2}{l}{ The values are represented as the Mean \pm SD }
\end{tabular}

The values are represented as the Mean \pm SD.

and its latency in experimental animals was effectively modulated by varying doses of the extract relative to controls (Figs. 1 and 2). As shown, the seed extract at $200 \mathrm{mg} / \mathrm{kg}$ had a maximal effect of $704 \%$ for lacking resolving reflex, while diazepam $0.50 \mathrm{mg} / \mathrm{kg}$ had a $529 \%$ effect (Table 3).

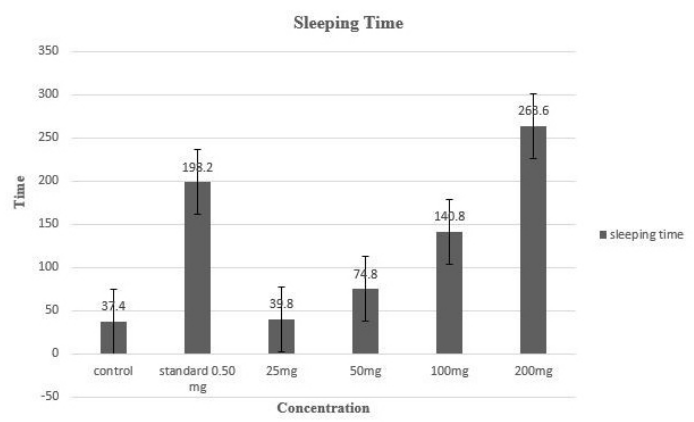

Fig. 1. The effect of Citruslimon (lemon) seed extracts on thiopental-Na stimulated sleeping time in mice $(n=5)$.

3.3 Central nervous system (CNS) depressant activity observed in animals treated with lemon seed extract as indicated by hole cross method

In the hole cross arrangement, the number of holes crossed from one compartment to another was recorded in intervals ranging from 30 to $120 \mathrm{~min}$. It was observed that the seed extracts at 50 and $100 \mathrm{mg} / \mathrm{kg}$ doses caused a reduction of activity in the animals (Fig. 3). Robust $(p<0.05)$ data have been obtained in dose-dependent terms (Table 4 ). In this study, evaluation at the 5 th period demonstrated a median of $69 \%$ suppression of locomotors activity by seed extract at $100 \mathrm{mg} / \mathrm{kg}$. In the same experimental set-up, diazepam demonstrated $53 \%$ suppression of the activity.

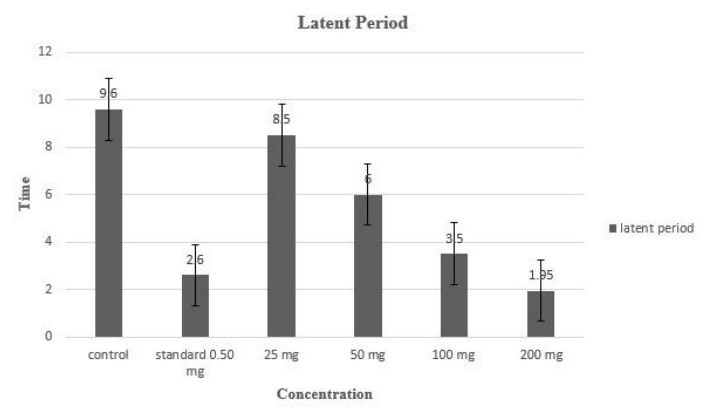

Fig. 2. The effect of Citruslimon (lemon) seed extracts on thiopental-Na induced latent period on mice $(n=5)$.

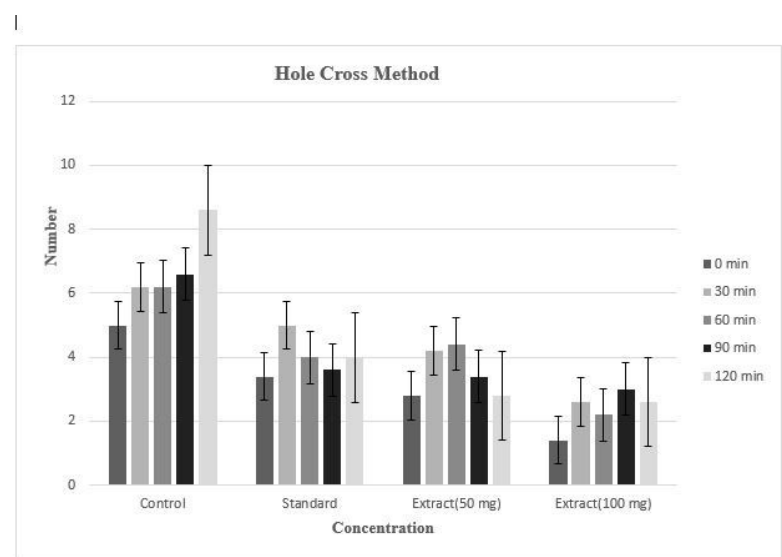

Fig. 3. CNS depressant activity of Citrus limon (lemon) seed extracts by hole cross method $(n=5)$.

\subsection{CNS depressant activity induced by lemon seed extracts in treated animals as indicated by hole board method}

The evaluation of CNS depressant activity by seed extracts provided some interesting results based on the dosage $(p<0.05)$. The extract resulted in significantly minimizing of head-dips in the treated animals in the hole-board test (Fig. 4). The $100 \mathrm{mg} / \mathrm{kg}$ dose of seed extract resulted in the suppression of movement (72\%), which was stronger than the standard diazepam (67\%) (Table 5).

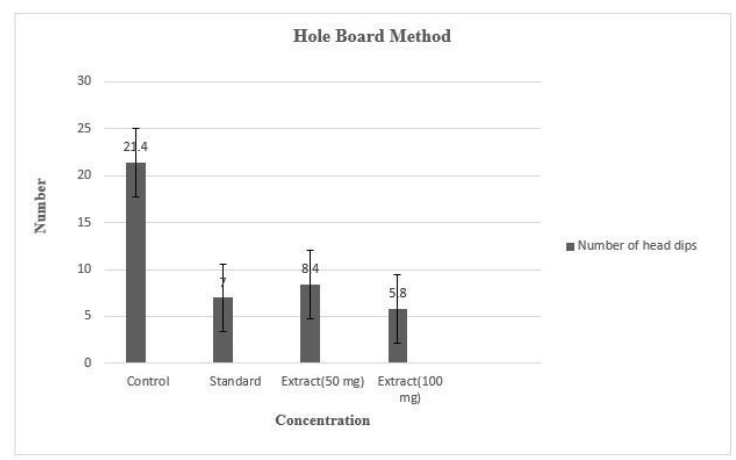

Fig. 4. CNS depressant activity of Citruslimon (lemon) seed ex tracts by hole board method $(n=5)$. 
Table 3. The effects of Citrus limon (lemon) seed extracts on the sleeping time of mice induced by thiopental-Na.

\begin{tabular}{lcccc}
\hline Group & Dose $(\mathrm{mg} / \mathrm{kg})$ & Latent period $(\mathrm{min})$ & Duration of sleep $(\mathrm{min})$ & \% Effect \\
\hline Control & $10 \mathrm{~mL} / \mathrm{kg}$ & $9.6 \pm 0.92$ & $37.4 \pm 1.4$ & 0 \\
Standard (Diazepam) & 0.50 & $2.6 \pm 0.24$ & $198.2 \pm 4.71$ & 529.94 \\
Seed extract & 25 & $8.5 \pm 0.44$ & $39.8 \pm 3.46$ & 106.41 \\
Seed extract & 50 & $6.00 \pm 0.44$ & $74.8 \pm 4.12$ & 200.00 \\
Seed extract & 100 & $3.5 \pm 0.22$ & $140.8 \pm 5.44$ & 376.47 \\
Seed extract & 200 & $1.95 \pm 0.16$ & $263.6 \pm 4.6$ & 704.81 \\
\hline Values are represented as Mean \pm SEM $(n=5), p<0.05$, that is the comparing the control group \\
significantly (two-way ANOVA followed by Bonferroni's test).
\end{tabular}

Table 4. Neuropharmacological potential test of Citrus limon (lemon) seed extracts by Hole cross method.

\begin{tabular}{|c|c|c|c|c|c|c|}
\hline \multirow{2}{*}{ Group } & \multirow{2}{*}{ Dose $(\mathrm{mg} / \mathrm{kg})$} & \multicolumn{5}{|c|}{ Quantity of moves (\% of movements Inhibition) } \\
\hline & & $0 \min$ & $30 \mathrm{~min}$ & $60 \mathrm{~min}$ & $90 \mathrm{~min}$ & $120 \mathrm{~min}$ \\
\hline Control & $10 \mathrm{~mL} / \mathrm{kg}$ & $5.0 \pm 0.70$ & $6.2 \pm 0.37$ & $6.2 \pm 0.48$ & $6.6 \pm 0.40$ & $8.6 \pm 0.24$ \\
\hline Standard & 1 & $3.4 \pm 0.92$ & $5.0 \pm 1.48$ & $4.0 \pm 1.30$ & $3.6 \pm 0.60$ & $4.0 \pm 0.63$ \\
\hline Seed extract & 50 & $2.8 \pm 1.15$ & $4.2 \pm 1.15$ & $4.4 \pm 0.67$ & $3.4 \pm 0.67$ & $2.8 \pm 0.58$ \\
\hline Seed extract & 100 & $1.4 \pm 0.50$ & $2.6 \pm 0.50$ & $2.2 \pm 0.48$ & $3.0 \pm 0.94$ & $2.6 \pm 0.81$ \\
\hline
\end{tabular}

Table 5. Neuropharmacological potential test of Citruslimon (lemon) seed extracts by hole board method.

\begin{tabular}{lccc}
\hline Group & Dose $(\mathrm{mg} / \mathrm{kg})$ & Quantity of head dips & \% Inhibition \\
\hline Control & $10 \mathrm{~mL} / \mathrm{kg}$ & $21.4 \pm 2.97$ & 0 \\
Standard & 1 & $7 \pm 0.70$ & $67.28 \%$ \\
Seed extract & 50 & $8.4 \pm 0.81$ & $60.74 \%$ \\
Seed extract & 100 & $5.8 \pm 0.37$ & $72.89 \%$ \\
\hline
\end{tabular}

Values are represented as Mean $\pm \operatorname{SEM}(n=5), p<0.05$, that is the comparing the control group significantly (two-way ANOVA followed by Bonferroni's test).

\subsection{CNS depressant activity observed in animals treated with lemon seed extracts as indicated by the open-field method}

The extracts substantially reduced the locomotor activity in tested mice at 50 and $100 \mathrm{mg} / \mathrm{kg}$ doses $(p<0.05)$. This result was noticeable from the underlying perception duration (0 min) and was consistent with the fifth perception duration (120 min) (Fig. 5). From the 2nd inspection to the 5th inspection, diazepam $(1 \mathrm{mg} / \mathrm{kg})$ demonstrated a substantial decline in locomotor activity in mice. This test showed a maximum of $36 \%$ suppression of locomotor function with seed extract at $100 \mathrm{mg} / \mathrm{kg}$, while $37 \%$ was reported with the standard drug diazepam (Table 6).

\section{Discussion}

Traditional medicines have been considered an original form of therapeutic approach that has been inexpensive and effective since ancient times. Recent efforts have focused on including neurobehavioral function and efficiency to complement modern medication with different ethnomedicinal products. Sedative properties for such bioactive compounds and natural products have been explored with standard protocols like hole-cross and free field experiments that can eval-

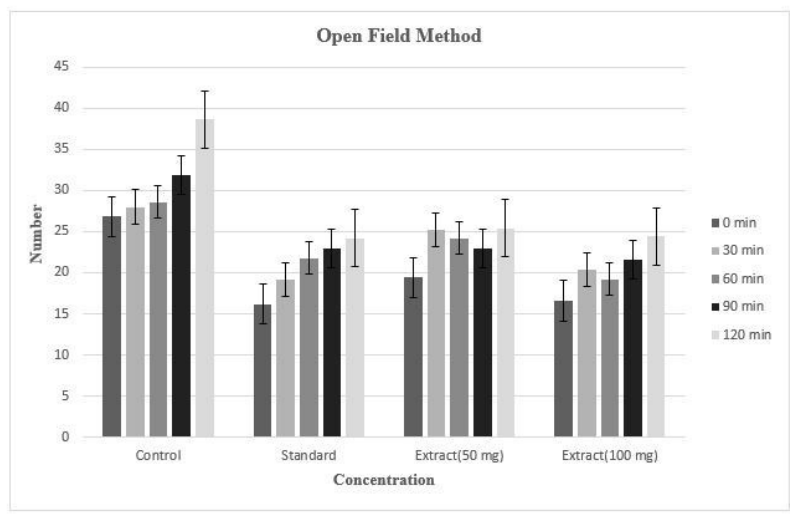

Fig. 5. CNS depressant activity of Citrus limon (lemon) seed extracts by open-field method $(n=5)$.

uate and record the naturalistic locomotor behavior of mice or its alteration under induced conditions. Our findings indicate that the oral administration of the experimental plant seed extract at the doses (50 and $100 \mathrm{mg} / \mathrm{kg}$ ) resulted in a significant decrease in the count of holes passed (Table 4). The repressive behavior was shown at $30 \mathrm{~min}$ when the extracts were given and persisted for $120 \mathrm{~min}$. The extracts at the studied doses induced a substantial locomotion reduction that was observed in the open field test from $30 \mathrm{~min}$ to $120 \mathrm{~min}$ during the inspected duration (Table 6). It is known that by observing the total distance, the open field test can be used to evaluate the anxiety behavior. In the current study, the resting time's range was between 6-12 seconds, the duration of time spent in center squares was $3 \mathrm{~min}$, and the distance traveled into the center squares was between the ranges of $8.5 \mathrm{~m}^{2}-19.3 \mathrm{~m}^{2}$. The findings demonstrated that the extract reduced the locomotor activity, supporting the extract's CNS 
Table 6. Neuropharmacological potential test of Citrus limon (lemon) seed extracts by the open-field method.

\begin{tabular}{|c|c|c|c|c|c|c|}
\hline \multirow{2}{*}{ Group } & \multirow{2}{*}{ Dose $(\mathrm{mg} / \mathrm{kg})$} & \multicolumn{5}{|c|}{ Quantity of moves (\% of movements Inhibition) } \\
\hline & & $0 \mathrm{~min}$ & $30 \mathrm{~min}$ & $60 \mathrm{~min}$ & $90 \mathrm{~min}$ & $120 \mathrm{~min}$ \\
\hline Control & $10 \mathrm{~mL} / \mathrm{kg}$ & $26.8 \pm 1.56$ & $28.0 \pm 2.38$ & $28.6 \pm 2.15$ & $31.8 \pm 2.13$ & $38.6 \pm 2.50$ \\
\hline Standard & 1 & $16.2 \pm 4.11$ & $19.2 \pm 5.95$ & $21.8 \pm 5.84$ & $23.0 \pm 5.50$ & $24.2 \pm 5.66$ \\
\hline Seed extract & 50 & $19.4 \pm 3.18$ & $25.2 \pm 3.15$ & $24.2 \pm 3.30$ & $23.0 \pm 2.60$ & $25.4 \pm 2.63$ \\
\hline Seed extract & 100 & $16.6 \pm 2.20$ & $20.4 \pm 3.23$ & $19.2 \pm 1.74$ & $21.6 \pm 2.13$ & $24.4 \pm 2.48$ \\
\hline
\end{tabular}

depressant effects. As shown, both tests resulted in a significant reduction in movement in the tested mice (Tables 4 and 6).

Moreover, the seed extracts reduced the sleep latency in the thiopental sodium-mediated sleeping time test (Fig. 2) and prolonged the sleep periods (Fig. 1) depending on the doses and demonstrated substantial sedative effects. Both tests suggestively diminished locomotion in all Swiss albino mice treated with the standard and seed extracts. Animal head-dipping behavior remains closely correlated with their psychological response. Gamma amino-butyric acid (GABA) can modulate the central nervous system through the voltage-gated $\mathrm{Ca}^{2+}$ channel or chlorine conductance [4050]. It was revealed that the animals' head-dipping behavior is clearly relevant to their mental state, and this test is used to investigate anxiety-related activities. Based on the research findings, it was hypothesized that an increase in head-dipping behavior could indicate an anxiolytic state in animals. At the same time, a decrease in the number of head dips was related a depressive impact [31]. Thus, the reduced head dipping behavior and improved sleeping time of mice in our study may relate to the inhibitory effect of the extract on neuronal activity, similar to the inhibition induced by GABA [51-56]. The therapeutic benefits of traditional medications might amalgamate a combination of constituents that could serve as an adjuvant to the conventional regimen. Multiple studies have reported that phytochemical compounds possess sedative and hypnotic effects, including tannins which can cause nonspecific CNS depression [56-58]. Several such action mechanisms have been proposed for alkaloids, flavonoids, steroids, as well as terpenoids, including activation of protein kinase C, neuroprotection against oxidative and metabolic insults; enhancing nicotinic receptors that also elevate the sensation and memory; energizing and improving nervous function; activating the transient receptor calcium channels in the membrane of the nerve cell which have neuropharmacological influence [59-67].

\section{Conclusions}

Recent studies in literature have reported the pharmacological benefits of the lemon constituents on the neurological well-being [68-70].The current study provides evidence of the pharmacological properties of Citrus limon (lemon) seed extract in complementing the effects of thiopental sodium by restricting the locomotor activity in the mice model.
Thiopental sodium is a standard drug for the induction of anaesthesia and hypnosis. The reduction in the sleep onset and an enhanced sleep duration induced in this drug model by the lemon seed extract provide a potential adjuvant for the qualitative augmentation of the existing protocols. The decrease in unconstrained locomotors and explorative properties further demonstrates the anxiolytic potential of the extract. However, further studies are warranted to investigate the plausible modes of action responsible for such neuropharmacological effects of Citrus limon (lemon) seed extract. The study broadens the scope of the lemon fruit as a nutraceutical or functional food with neuro-modulatory pharmacological properties.

\section{Abbreviations}

C. limon, Citrus limon; Ltd, limited; BDH, British Drug House; HCL, Hydrochloric acid, Normality; M, Molarity; b.w, body weight; CNS, Central nervous system; GABA, Gamma amino-butyric acid.

\section{Author contributions}

MMR-Experimental work; FI-Experimental work; AP: Experimental work; MAKA-Statistical analysis; GMAConceptualization and Analysis; MFU-Study Design, Analysis and manuscript writing; MA-Conceptualization, Study design, Analysis and Manuscript writing.

\section{Ethics approval and consent to participate}

Animals were obtained from Jahangirnagar University, Dhaka, Bangladesh. All protocols considered in our study, including animals, were approved by the Faculty of Allied Health Sciences Research Ethics Committee, Daffodil International University, Dhaka-1207, Bangladesh. (Ref: FAHSREC/DIU/2020/1006).

\section{Acknowledgment}

The authors are grateful to the Department of Pharmacy, Jahangirnagar University, Dhaka, Bangladesh for providing experimental animals. The authors also condole the sudden demise of Dr. Sharif Mohammad Shaheen and gratefully acknowledge his contribution to this work. 


\section{Funding}

This work was funded by the Deanship of Scientific Research (DSR), King Abdulaziz University, Jeddah, Saudi Arabia under grant no. (KEP-1-141-41). The authors, therefore, acknowledge with thanks DSR technical and financial support.

\section{Conflict of interest}

The authors declare no conflict of interest.

\section{References}

[1] Ferdous M, Daula ASU, Naznin S, Yeasmin F, Basher MA. Analgesic, anxiolytic and sedative-like activities of leaves of Alpinia calcarata Roscoe in mice. Journal of Medicinal Plants Research. 2020; 14: $155-163$.

[2] Islam N, Khan MF, Khatun MR, Nur S, Hanif NB, Kulsum $\mathrm{U}$, et al. Neuropharmacological insights of African oil palm leaf through experimental assessment in rodent behavioral model and computer-aided mechanism. Food Bioscience. 2021; 40: 100881.

[3] Liu J, Wei W, Peng Q, Guo Y. How does Perceived Health Status Affect Depression in Older Adults? Roles of Attitude toward Aging and Social Support. Clinical Gerontologist. 2021; 44: 169-180.

[4] Greene T, Harju-Seppänen J, Adeniji M, Steel C, Grey N, Brewin $\mathrm{CR}$, et al. Predictors and rates of PTSD, depression and anxiety in UK frontline health and social care workers during COVID-19. European Journal of Psychotraumatology. 2021; 12: 1882781.

[5] Verma R, Bhatia R, Singh G, Kumar B, Mehan S, Monga V. Design, synthesis and neuropharmacological evaluation of new 2,4disubstituted-1,5-benzodiazepines as CNS active agents. Bioorganic Chemistry. 2020; 101: 104010.

[6] Rubab S, Rizwani GH, Bahadur S, Shah M, Alsamadany H, Alzahrani $\mathrm{Y}$, et al. Neuropharmacological potential of various morphological parts of Camellia sinensis L. Saudi Journal of Biological Sciences. 2020; 27: 567-573.

[7] Kara S, Yazici KM, Güleç C, Ünsal I. Mixed anxiety-depressive disorder and major depressive disorder: comparison of the severity of illness and biological variables. Psychiatry Research. 2000; 94: 59-66.

[8] Khan A, Jahan S, Alshahrani S, Alshehri BM, Sameer AS, Arafah A, et al. Phytotherapeutic agents for neurodegenerative disorders: a neuropharmacological review. Phytomedicine. 2021; 26: 581620.

[9] Hassan W, Silva CEB, Mohammadzai IU, da Rocha JBT, J L. Association of oxidative stress to the genesis of anxiety: implications for possible therapeutic interventions. Current Neuropharmacology. 2014; 12: 120-139.

[10] Beckhauser TF, Francis-Oliveira J, De Pasquale R. Reactive Oxygen Species: Physiological and Physiopathological Effects on Synaptic Plasticity: Supplementary issue: Brain plasticity and repair. Journal of Experimental Neuroscience. 2016; 10: 23-48.

[11] García-Gutiérrez MS, Navarrete F, Gasparyan A, AustrichOlivares A, Sala F, Manzanares J. Cannabidiol: a potential new alternative for the treatment of anxiety, depression, and psychotic disorders. Biomolecules. 2020; 10: 1575.

[12] Jyoti MA, Barua N, Hossain MS, Hoque M, Bristy TA, Mahmud $\mathrm{S}$, et al. Unravelling the biological activities of the Byttneria pilosa leaves using experimental and computational approaches. Molecules. 2020; 25: 4737.

[13] Ali M, Sayem SAJ, Quah Y, Lee E-B, Birhanu BT, Suk K, et al. Investigation of Potential Antioxidants, Thrombolytic and Neuropharmacological Activities of Homalomena aromatica Leaves Using Experimental and In Silico Approaches. Molecules. 2021; 26: 975.

[14] Dev C, Nidhi S. Basketful benefit of Citrus limon. International Research Journal of Pharmacy. 2016; 7: 1-3.

[15] Morton JF. Fruits of warm climates. Creative Resource Systems. Inc.: Winterville, USA. 1987:18-22.

[16] Singh A, Saini ML, Behl RK. Screening of citrus rootstocks for salt tolerance in semi-arid climates - a review. Tropics. 2003; 13: 53-66.

[17] Faddetta T, Abbate L, Alibrandi P, Arancio W, Siino D, Strati F, et al. The endophytic microbiota of Citrus limon is transmitted from seed to shoot highlighting differences of bacterial and fungal community structures. Scientific Reports. 2021; 11: 7078.

[18] Noshad M, Alizadeh Behbahani B, Jooyandeh H, Rahmati-Joneidabad M, Hemmati Kaykha ME, Ghodsi Sheikhjan M. Utilization of Plantago major seed mucilage containing Citrus limon essential oil as an edible coating to improve shelf-life of buffalo meat under refrigeration conditions. Food Science \& Nutrition. 2021; 9: 1625-1639.

[19] Sevindik E, Aydın S, Sujka M, Apaydın E, Yıldırım K, Palas G. GCMS Analysis and Evaluation of Antibacterial and Antifungal Activity of Essential Oils Extracted from Fruit Peel of Citrus aurantium L. (Rutaceae) Grown in the West Anatolian Area. ErwerbsObstbau. 2021; 63: 135-142.

[20] Bora H, Kamle M, Mahato DK, Tiwari P, Kumar P. Citrus essential oils (CEOs) and their applications in food: An overview. Plants. 2020; 9: 357.

[21] Roy S, Nath D, Paul P, Chakraborty S. Computational identification of conserved microRNAs and functional annotation of their target genes in Citrus limon. South African Journal of Botany. 2020; 130: 109-116.

[22] González-Mas MC, Rambla JL, López-Gresa MP, Blázquez MA Granell A. Volatile compounds in citrus essential oils: A comprehensive review. Frontiers in Plant science. 2019; 10: 12.

[23] Klimek-Szczykutowicz M, Szopa A, Ekiert H. Citrus limon (Lemon) phenomenon-a review of the chemistry, pharmacological properties, applications in the modern pharmaceutical, food, and cosmetics industries, and biotechnological studies. Plants. 2020; 9: 119.

[24] Abad-García B, Garmón-Lobato S, Berrueta LA, Gallo B, Vicente F. On line characterization of 58 phenolic compounds in Citrus fruit juices from Spanish cultivars by high-performance liquid chromatography with photodiode-array detection coupled to electrospray ionization triple quadrupole mass spectrometry. Talanta. 2012; 99: 213-224.

[25] García-Salas P, Gómez-Caravaca AM, Arráez-Román D, SeguraCarretero A, Guerra-Hernández E, García-Villanova B, et al. Influence of technological processes on phenolic compounds, organic acids, furanic derivatives, and antioxidant activity of whole-lemon powder. Food Chemistry. 2013; 141: 869-878.

[26] Russo M, Bonaccorsi I, Costa R, Trozzi A, Dugo P, Mondello L. Reduced time HPLC analyses for fast quality control ofcitrusessential oils. Journal of Essential Oil Research. 2015; 27: 307-315.

[27] Ortega F, Arce VB, Garcia MA. Nanocomposite starch-based films containing silver nanoparticles synthesized with lemon juice as reducing and stabilizing agent. Carbohydrate Polymers. 2021; 252: 117208 .

[28] Ramassamy C. Emerging role of polyphenolic compounds in the treatment of neurodegenerative diseases: a review of their intracellular targets. European Journal of Pharmacology. 2006; 545: 51-64.

[29] Olas B. A review of in vitro studies of the anti-platelet potential of citrus fruit flavonoids. Food and Chemical Toxicology. 2021; 150: 112090.

[30] Bardak A, Çelik S, Erdoğan O, Ekinci R, Dumlupinar Z. Association Map-ping of Verticillium Wilt Disease in a Worldwide Collection of Cotton (Gossypium hirsutum L.). Plants. 2021; 10: 306

[31] Hafiz W, Zilani MNH, Sultana NA, Isalm MM, Anisuzzman M, Hossain MG. Neuropharmacological potential of Ceriscoides turgida (Roxb.) leaf and root in mice. Clinical Phytoscience. 2019; 5: 5.

[32] Patra JK, Dhal NK, Thatoi HN. In vitro bioactivity and phytochemical screening of Suaeda maritima (Dumort): a mangrove associate from Bhitarkanika, India. Asian Pacific Journal of Tropical Medicine. 2011; 4: 727-734.

[33] Amorim EL, Nascimento JE, Monteiro JM, Peixoto Sobrinho T, Araújo TA, Albuquerque UP. A simple and accurate procedure for 
the determination of tannin and flavonoid levels and some applications in ethnobotany and ethnopharmacology. Functional Ecosystems and Communities. 2008; 2: 88-94.

[34] Kumar AR, Subburathinam K, Prabakar G. Phytochemical screening of selected medicinal plants of asclepiadaceae family. Asian Journal of Microbiology, Biotechnology \& Environmental Sciences. 2007; 9: 177-180.

[35] Edeoga HO, Okwu D, Mbaebie B. Phytochemical constituents of some Nigerian medicinal plants. African journal of biotechnology. 2005; 4: 685-688.

[36] Raihan MO, Habib MR, Brishti A, Rahman MM, Saleheen MM, Manna M. Sedative and anxiolytic effects of the methanolic extract of Leea indica (Burm. f.) Merr. leaf. Drug Discoveries \& Therapeutics. 2011; 5: 185-189.

[37] Uddin SJ, Shilpi JA, Rahman MT, Ferdous M, Rouf R, Sarker SD. Assessment of neuropharmacological activities of Pandanus foetidus (Pandanaceae) in mice. Die Pharmazie. 2006; 61: 362364.

[38] Kamei J, Matsunawa Y, Miyata S, Tanaka S, Saitoh A. Effects of nociceptin on the exploratory behavior of mice in the hole-board test. European Journal of Pharmacology. 2004; 489: 77-87.

[39] Gould TD, Dao DT, Kovacsics CE. The Open Field Test. Mood and Anxiety Related Phenotypes in Mice. 2009; 6: 1-20.

[40] Zhao L, Sun Z, Yang L, Cui R, Yang W, Li B. Neuropharmacological effects of Aconiti Lateralis Radix Praeparata. Clinical and Experimental Pharmacology and Physiology. 2020; 47: 531-542.

[41] Araújo JRC, Campos AR, de Barros M.V. Damasceno M, Santos SAAR, Ferreira MKA, de Azevedo Moreira R, et al. Neuropharmacological Characterization of Dioclea altissima Seed Lectin (DAL) in Mice: Evidence of Anxiolytic-like Effect Mediated by Serotonergic, GABAergic Receptors and no Pathway. Current Pharmaceutical Design. 2020; 26: 3895-3904.

[42] Kumar K, Sharma S, Kumar P, Deshmukh R. Therapeutic potential of GABA(B) receptor ligands in drug addiction, anxiety, depression and other CNS disorders. Pharmacology, Biochemistry, and Behavior. 2013; 110: 174-184.

[43] Wojcieszak J, Andrzejczak D, Wojtas A, Gołembiowska K, Zawilska JB. Comparative neuropharmacological studies on three pyrrolidine-containing synthetic cathinones. Forensic Toxicology. 2020; 38: 378-393.

[44] Shams-Ud-Doha K, Al Mahmud Z, Bachar SC, Qais N. Antinociceptive, anti-inflammatory, antimicrobial and central nervous system depressant activities of ethanolic extract of leaves and roots of Gomphostemma parviflorum var. parviflorum wall. Pharmacognosy Research. 2013; 5: 233-240.

[45] Sultana T, Mannan MA, Ahmed T. Evaluation of central nervous system (CNS) depressant activity of methanolic extract of Commelina diffusa Burm. in mice. Clinical Phytoscience. 2018; 4: 1-7.

[46] Iqbal J, Khan A, Muhammad S, Jan SU, Gul R. Analgesic and neuropharmacological activities of Berberis lycium Royle collected from district Sherani Balochistan, Pakistan. Pakistan Journal of Pharmaceutical Sciences. 2020; 33: 1689-1695.

[47] Fernández S, Wasowski C, Paladini AC, Marder M. Sedative and sleep-enhancing properties of linarin, a flavonoid-isolated from Valeriana officinalis. Pharmacology, Biochemistry, and Behavior. 2004; 77: 399-404.

[48] Sohi S, Shri R. Neuropharmacological potential of the genus Citrus: A review. Journal of Pharmacognosy and Phytochemistry. 2018; 7: 538-548.

[49] Sarker SD, Uddin SJ, Shilpi JA, Rouf R, Ferdous M, Nahar L. Neuropharmacological properties of Xylocarpus moluccensis. Fitoterapia. 2007; 78: 107-111.

[50] McLaughlin I, Dani JA, De Biasi M. Nicotine withdrawal. Current Topics in Behavioral Neurosciences. 2015; 24: 99-123.

[51] Jakaria M, Cho D, Ezazul Haque M, Karthivashan G, Kim I, Ganesan P, et al. Neuropharmacological Potential and Delivery Prospects of Thymoquinone for Neurological Disorders. Oxidative Medicine and Cellular Longevity. 2018; 2018: 1-17.

[52] Ali A, Ahmad FJ, Pillai KK, Vohora D. Evidence of the antiepilep- tic potential of amiloride with neuropharmacological benefits in rodent models of epilepsy and behavior. Epilepsy \& Behavior. 2004; 5: 322-328.

[53] Jang J, Son Y, Kang SS, Bae C, Kim J, Kim S, et al. Neuropharmacological Potential of Gastrodia elataBlume and its Components. Evidence-Based Complementary and Alternative Medicine. 2015; 2015: 1-14.

[54] Schulte C, Maric HM. Expanding GABAAR pharmacology via receptor-associated proteins. Current Opinion in Pharmacology. 2021; 57: 98-106.

[55] Goni O, Khan MF, Rahman MM, Hasan MZ, Kader FB, Sazzad $\mathrm{N}$, et al. Pharmacological insights on the antidepressant, anxiolytic and aphrodisiac potentials of Aglaonema hookerianum Schott. Journal of Ethnopharmacology. 2021; 268: 113664.

[56] Toth M. Epigenetic Neuropharmacology: Drugs Affecting the Epigenome in the Brain. Annual Review of Pharmacology and Toxicology. 2021; 61: 181-201.

[57] Tiwari R, Latheef SK, Ahmed I, Iqbal HMN, Bule MH, Dhama $\mathrm{K}$, et al. Herbal Immunomodulators - a Remedial Panacea for Designing and Developing Effective Drugs and Medicines: Current Scenario and Future Prospects. Current Drug Metabolism. 2018; 19: 264-301.

[58] Dey P, Chandra S, Chatterjee P, Bhattacharya S. Neuropharmacological properties of Mikania scandens (L.) Willd. (Asteraceae). Journal of Advanced Pharmaceutical Technology \& Research. 2011; 2: 255-259.

[59] Kinda PT, Zerbo P, Guenné S, Compaoré M, Ciobica A, Kiendrebeogo M. Medicinal Plants used for Neuropsychiatric Disorders Treatment in the Hauts Bassins Region of Burkina Faso. Medicines. 2017; 4: 32.

[60] Kumar GP, Anilakumar KR, Naveen S. Phytochemicals Having Neuroprotective Properties from Dietary Sources and Medicinal Herbs. Pharmacognosy Journal. 2015; 07: 01-17.

[61] Moreira LK, de Brito AF, Fontana C, de Carvalho FS, Sanz G, Vaz BG, et al. Neuropharmacological assessment in mice and molecular docking of piperazine derivative LQFM212. Behavioural Brain Research. 2020; 394: 112827.

[62] Saha PS, Sarkar S, Jeyasri R, Muthuramalingam P, Ramesh M, Jha $S$. In vitro propagation, phytochemical and neuropharmacological profiles of Bacopa monnieri (L.) Wettst.: a review. Plants. 2020; 9: 411.

[63] Mohammed Sur T, Akbaba E, Hassan SA, Bagci E. Neuropharmacological profile of Hypericum scabrum L. essential oil in rats. Journal of Essential Oil Research. 2020; 32: 79-87.

[64] Arumugam V, John VS, Augustine N, Jacob T, Joy SM, Sen S, et al. The impact of antidepressant treatment on brain-derived neurotrophic factor level: an evidence-based approach through systematic review and meta-analysis. Indian Journal of Pharmacology. 2017; 49: 236-242.

[65] Akter M, Afroze M, Khatun A. Evaluation of analgesic, neuropharmacological and cytotoxic activity of Trigonella foenumgraecum Linn. International Current Pharmaceutical Journal. 2011; 1: 6-11.

[66] Zafar Imam M, Sultana S, Akter S. Antinociceptive, antidiarrheal, and neuropharmacological activities of Barringtonia acutangula. Pharmaceutical Biology. 2012; 50: 1078-1084.

[67] Jiji K, Muralidharan P. Neuropharmacological Potential of Clitoria ternatea Linn.-A Review. Research Journal of Pharmacy and Technology. 2020; 13: 5497-5502.

[68] Khan A, Ikram M, Hahm JR, Kim MO. Antioxidant and AntiInflammatory Effects of Citrus Flavonoid Hesperetin: Special Focus on Neurological Disorders. Antioxidants. 2020; 9: 609.

[69] Mamede AMGN, de Souza Coelho CC, Freitas-Silva O, Barboza HTG, Soares AG. Lemon. In Jaiswal AK (ed.) Nutritional Composition and Antioxidant Properties of Fruits and Vegetables (pp. 377-392). Academic Press: Cambridge MA. 2020.

[70] Nuzzo D, Picone P, Giardina C, Scordino M, Mudò G, Pagliaro $\mathrm{M}$, et al. New Neuroprotective Effect of Lemon IntegroPectin on Neuronal Cellular Model. Antioxidants. 2021; 10: 669. 